\title{
IMPLEMENTASI MODEL PEMBELAJARAN PICTURE AND PICTURE PADA SISWA KELAS VIII MATERI BANGUN RUANG SISI DATAR
}

\author{
Muchamad Teguh Setiawan \\ Pendidikan Matematika STKIP PGRI Sidoarjo \\ teguh.setiawan131996@gmail.com \\ Risdiana Chandra Dhwey \\ Pendidikan Matematika STKIP PGRI Sidoarjo \\ chandra.statistika.its@gmail.com \\ Eka Nurmala Sari Agustina \\ Pendidikan Matematika STKIP PGRI Sidoarjo \\ eka.agustina.15@gmail.com
}

\begin{abstract}
Abstrak:
Implementasi adalah suatu cara pelaksanaan kegiatan yang terencana secara rapi, cermat dan rinci untuk memperoleh hasil yang efektif dan efisien yang di tinjau dari aktivitas guru, aktivtas siswa, hasil belajar dan respons siswa. supaya membuat siswa berperan aktif dalam proses pembelajaran dan agar siswa tidak bingung dengan banyaknya rumus yang ada di materi bangun ruang sisi datar, maka dapat mengimplementasikan mode pembelajaran picture and picture dimana metode pembelajaran ini siswa harus aktif yang menggunakan gambar dan dipasangkan atau diurutkan menjadi urutan yang sistematis, seperti menyusun gambar secara berurutan, menunjukkan gambar, memberi keterangan gambar dan mejelaskan gambar. Penelitian ini merupakan penelitian deskriptif kuantitatif, data yang diperoleh dari sampel populasi penelitian dianalisis sesuai dengan metode statistik yang digunakan kemudian diinterprestasikan. Karena penelitian ini ingin mengetahui Implementasi model pembelajaran picture and picture kelas VIII di SMP Bilingual Terpdu pada materi bangun ruang sisi datar. Pada pelaksanaan model pembelajaran picture and picture pada penelitian ini nilai aktivitas guru menujukan 3,08 di kategori "baik", pada bagian aktivitas siswa dari 12 indikator mendapatkan 8 sangat aktif dan 4 aktif. Pada bagian nilai hasil belajar secara klasikal mendapatkan 62,5\% ini menunjukan bahwa secara klasikal dikatakan "belum tuntas". Dan dari respons siswa dinyatakan positif karena angket respons pada kriteria "baik".
\end{abstract}

Kata Kunci: picture and picture, implementasi, bagun ruang sisi datar

\begin{abstract}
:
Implementation is a way of activity which is planned orderly, carefully and specifically to gain the effective and efficient result which is reviewed from the teacher's activity, students' activity, study's result and students' responses in order to make the students actively act in the process of learning and the students will not confuse with many formulas found in the material of build space flat side, thus can implemented picture and picture model learning where this learning metode, the student must be active to use the picture and to be matched or sorted to be systematic sequence, such as arrange the picture orderly, appoint the picture, give information about the picture and explain the picture. This research was a descriptive quantitative research, the data gained from the research population sample which analyzed coincide with the statistic metode which was used then interpreted. Because of this research intended to know the implementation of learning mode of picture and picture in the VIII grade in Bilingual
\end{abstract}


Terpadu Junior High School in the material of build space of flat side. In the implementation learning mode of picture and picture in this research, the score of teacher's actixxity showed that 3,08 in the "good" category, in the part students' activity from 12 indicator gained 8 very active and 4 active. In the part score of learning result classically gained $62,5 \%$, this showed that classically can be said "incompleted" and from the students' responses was positive stated because the response questionnaire in the "good" category.

Keywords: picture and picture, implementation, flat side space building

\section{PENDAHULUAN}

Proses pembelajaran mempunyai peranan penting dalam keberhasilan pembelajaran, seperti yang diungkapkan oleh Rusman (2015) "mengatakan Proses pembelajaran harus dengan sengaja, diorganisasikan dengan baik agar dapat menumbuhkan proses belajar yang baik untuk dapat mencapai hasil belajar yang optimal. Dalam proses pembelajaran, peserta didik akan memperoleh hasil belajar yang merupakan kemampuan yang dimiliki siswa setelah ia menerima pengalaman belajarnya yaitu proses pembelajaran akan berhasil apabila proses pembelajaran yang terjadi berjalan dengan baik dan lancar pada seluruh mata pelajaran.”

Menurut Suprjiono (dalam Natalina ; 2009) "mengatakan pembelajaran kooperatif picture and picture adalah salah satu metode pembelajaran aktif yang menggunakan gambar dan dipasangkan atau diurutkan menjadi urutan yang sistematis, seperti menyusun gambar secara berurutan, menunjukkan gambar, memberi keterangan gambar dan mejelaskan gambar." Menurut Biehler (dalam Fauzi, 2011)"mengatakan Picture and picture merupakan pembelajaran kooperatif yang menggunakan media gambar sehingga dapat menarik perhatian siswa serta dapat membangun motivasi siswa dalam belajar." Menurut Hamdani (dalam Rohima, 2017) “mengatakan Picture and picture adalah suatu teknik belajar yang menggunakan gambar dan dipasangkan atau diurutkan menjadi urutan logis." Berdasarkan dari pendapat Suprijono, Biehler, dan Hamdani dapat disimpulkan bahwa pembelajaran kooperatif seperti model pembelajaran picture and picture karena menggunakan media gambar yang disusunkan menjadi urutan logis seperti mencocokkan gambar bangun datar dengan rumus yang sesuai, serta dapat menarik perhatian siswa karna siswa tidak lagi diam saat pembelajaran tapi bisa dikatakan sangat aktif. Dari model pembelajaran picture and picture diharapkan siswa bisa termotivasi agar tidak lagi takut dengan mata pelajaran matematika, dan tidak lagi kesulitan dalam pembelajaran matematika khususnya dalam materi bangun datar.

Dari pembelajran picture and picture diduga cocok untuk materi bangun ruang sisi datar karena jadi lebih faham tentang materi ajar karena guru menunjukan gambar - gambar dan menjelaska tentang bab tersebut, dapat meningkatkan daya ingat karena siswa ditugaskan untuk mencocokan gambar dengan rumus yang benar, dan dapat meningkatkan rasa percaya diri siswa sebab guru 
menanyakan alasan siswa ketika mencocokan gambar dengan rumus dan guru mengajarkan cara penggunaan rumus setelah dicocokan.

\section{METODE}

Penelitian ini dilaksanakan di SMP Bilingual Terpadu Krian Sidoarjo, semester genap tahun ajaran 2019/2020. Penelitian ini merupakan deskriptif kuantitatif data dianalisis menggunakan metode statistik yang diperoleh dari sampel populasi kemudian diinterprestasikan. Karena penelitian ini ingin mengetahui Implementasi model pembelajaran picture and picture kelas VIII pada materi bangun datar, penelitian ini ditinjau dari aktifitas guru dalam mengelola kelas, aktivitas siswa dalam pembelajaran, hasil belajar siswa, dan respons siswa terhadap model pembelajaran.

\section{HASIL DAN PEMBAHASAN}

Penelitian ini dilakukan pada tanggal 14 Mei 2020 disekolah SMP Bilingula Terpadu Krian Sidoarjo. Karena adanya pandemi COVID 19 maka penelitian ini dilaksanakan melalui aplikasi ZOOM secara online yang diikuti oleh 8 siswa karena faktor semua siwa dari pesantren dan tidak semunya mempunyai ponsel atau laptop.

Hasil analisis observasi aktivitas guru pada kegiatan ini yaitu guru dalam menyampaikan model pembelajaran picture and picture memperoleh skor 3,08 dengan kategori baik, diantara kegiatan pendahuluan guru selalu menyiapkan siswa saat prmbrlajaran, dan seputar pertanyaan - pertanyaan yang diajukan guru seperti apersepsi untuk mengingatkan kembali materi yang suda dipelajari, guru menyampaikan tujuan pembelajaran.

Dikegiatan inti guru menunjukan gambar yang berisi benda - benda yang berhubungan dengan prisma dan limas dan guru menunjukan gambar yang berisi rumus prisma dan limas, maka proses pembelajaran menggunakan model picture and picture berlangsung dengan kondusif, kegiatan penutup guru dan siswa membuat kesimpulan, serta melakukan refleksi terhadap kegiatan yang suda dilaksanakan.

Hasil Observasi Aktivitas Siswa diperoleh rata - rata indikator pertama sebesar78,05\% indikator kedua sebesar $85,9 \%$ indikator ketiga sebesar $81,25 \%$ indikator keempat sebesar 76,5\% indikator kelima sebesar 73,4\% indikator keenam sebesar 76,5\% indikator ketujuh sebesar 70,25\% dan indikator kedelapan sebesar 78,1\%. Dapat disimpulkan bahwa pembelajaran dalam penerapan model picture and picture dikatakan aktif karena semua indikator menunjukan sangat baik.

Untuk indikator pertama memenuhi karena siswa memperhatikan saat guru menyampaikan kompetensi, indikator kedua memenuhi karena siswa memperhatikan guru saat memberikan apersepsi, indikator ketiga memenuhi karena siswa memperhatikan saat guru memberikan pernyataan 
picture and picture, indikator keempat memenuhi karena siswa dapat mencocokan gambar, indikator kelima memenuhi karena siswa bertaya saat menerpkan picture and picture, indikator keenam memenuhi karena siswa berpartisipasi mengerjakan latihan soal, indikator ketujuh memenuhi karena siswa dapat menjawab pertanyaan guru mengenai latihan soal, dan indikator kedelapan memenuhi karena siswa dapat menypulkan pelajaran yang di terima.

Data Hasil Tes Belajar Siswa diperoleh analisis tes hasil belajar siswa menunjukkan bahwa selama proses pembelajaran dengan menggunakan model pembelajaran picture and picture pada materi bangun ruang sisi datar dinyatakan tidak tuntas secara kelasikal secara online dengan persentase mencapai $62,5 \%$. Pada tabel 4.5 data hasil tes dari 8 siswa yang mendapatkan skor di atas KKM sebanyak 5 siswa dinyatakan tuntas, sedangkan 3 siswa dinyatakan tidak tuntas karena nilainya di bawah KKM. Peneiti menerapkan model pembelajaran picture and picture bisa dikatakan gagal karena rata - rata secara klasikal di kelas VIII - I dalam kategori belum tuntas, karena soal yang terlalu sulit termasuk dalam soal lanjuta.

Hasil angket respons siswa menunjukan bahwa respons siswa terhadap proses pembelajaran menggunakan model pembelajaran picture and pictture rata - rata siswa memberikan respons positif, karena dari 12 pernyataan respons siswa 8 respons sangat baik dan 4 respons baik, namun ada 2 pernyataan dari angket respons siswa memperoleh nilai rata - rata di bawah $70 \%$ seperti pernyataan "dalam pembelajaran menggunakan picture and picture motivasi saya untuk belajar semakin meningkat" dan pada pernyataan "saya setuju picture and picture diterpkan pada materi pelajaran lain" kedua pernyataan tersebut mendapatkan nilai rata - rata $68,77 \%$ dan $56,25 \%$ karena dari beberapa siswa belum tertarik mempelajari mata pelajaran matematika serta pada proses pembelajaran sebagian siswa masih ada yang kurang memahami materi yang diajarkan, oleh karena itu siswa lebih setuju kalau picture and picture diterapkan di matapelajaran lain, karena sebagian siswa masih ada yang beranggapan bahwa pelajaran matematika pelajaran yang sulit.

\section{SIMPULAN}

Berdasrkan paparan dan pembahasan model pembelajaran picture and picture diterapkan pada materi bangun ruang sisi datar kelas VIII - I SMP Bilingual Terpadu dapat disimpulkan sebagi berikut: Pada pelaksanaan model pembelajaran picture and picture pada penelitian ini nilai aktivitas guru menujukan 3,08 di kategori "baik". Pada pelaksanaan model pembelajaran picture and picture pada penelitian ini nilai aktivitas siswa dari penilaian 2 observer, dari 12 indikator mendapatkan 8 sangat aktif dan 4 aktif. Pada pelaksanaan model pembelajaran picture and picture pada penelitian ini nilai hasil belajar secara klasikal 62,5\% ini menunjukan bahwa secara klasikal dikatakan "belum tuntas". 
Pada pelaksanaan model pembelajaran picture and pictue ini, respons siswa dinyatakan positif karena angket respons berada pada kriteria "baik".

\section{REFERENSI}

Afandi, M.dkk (2013) "model dan metode pembelajaran di sekolah. Universitas Islam Sultan Agung Semarang."

Cahyaningrum, C. (2007). "Ringkasan dan bank soal matematika untuk SMP/MTs. Bandung: Yrama Widys".

Dimyati, (2002). Belajar dan pembelajran. Bandung: Rineka Cipta.

Diniati, I. (2019) penerapan strategi pembelajaran snowball throwing pada materi bangun datar ruang sisi datar di kelas VIII SMP AL - FALAH. STKIP PGRI SIDOARJO .

Fauzi, R.dkk (2011) "penerapan model pembelajaran picture and picture untuk meningkatkan motivasi belajar biologi siswa kelas VIII D SMPN 14 Surakarta Tahun 2011/2012. Universitas Negri Surakarta."

Hamzah, B.U. dkk. ( 2014). Perencanaan Belajar Dengan Pendekatan PAILKEM. Jakarta: PT Bumi Aksara.

Huda, Miftahul. 2011. "Cooperative Learning. Yogyakarta: Pustaka Pelajar."

Khabib, M.L. (2017).”Penerapan Pembelajaran Problem Based Learning pada materi pokok sistem persamaan linear dua variabel kelas X MA AL-ARIF Pasuruan. STKIP PGRI SIDOARJO."

Lubis, R.R (2017). "model pembelajaran Picture and Picture untuk meningkatkan hasil belajar siswa. Proseding seminar nasional tahunan fakultas ilmu sosial Universitas Negri Medan."

Natalina, dkk (2010). "Penerapan Model Pembelajaran Kooperatif Picture and Picture untuk Meningkatkan Aktivitas dan Hasil Belajar Biologi Siswa Kelas XI IPA SMAN 1 Ukui Tahun Ajaran 2009/2010."

Nurdyansyah, dkk (2015) "pengaruh strategi pembelajaran aktif terhadap hasil belajar pada Madarah Ibtidaiyah. Universitas Muhammdiyah Sidoarjo."

Rahmawati. N.I. (2017) "pengaruh model pembelajaran problem based introduction(PBI) terhadap prestasi belajar siswa pada pokok bahasan matriks di kelas XI SMK YPM 3 TAMAN tahun pelajaran 2017/2018. STKIP PGRI SIDOARJO."

Rohani, Ahmad. (2010). "PengelolaanPengajaran. Jakarta: RinekaCipta."

Rusman, (2015)“Model Pembelajaran Tematik Terpadu Teori, Praktik dan Penilaian. Jakarta: Rajawali Pers."

Sardiman. (2014). "Interaksi dan Motivasi Belajar Mengajar. Depok: PT Rajagrafindo Persada."

Somantri, M.dkk (2011) "revitalisasi kerja guru guna meningkatkan kompetensi dan profesionalisme guru SD/MI di kabupaten Seluma. Universitas Bengkulu."

Sudjana, N. (2008). "Penelitian hasil belajar mengajar. Bandung: Remaja Rosdakarya."

Suparno. (1997). "Filsafat Konstruktivisme Dalam Pendidikan. Jogjakarta. Kanisius."

Sudjana, N (2008). "Penelitian hasil proses belajar mengajar. Bandung: remaja Rosdakarya."

Utami.E (2013) "penggunaan model pembelajaran picture and pcture untuk meningkatkan keaktifan belajar siswa pada pembelajaran matematika di kelas IIA SD Islam Terpadu Arofah 1 Boyolali.Universitas Muhammadiyah Surakata”. 